One of the fundamental problems in writing the history of ecology is the fact, itself not at all unexpected, that few new trends or interpretations displaced previous views and practices. The science persists and advances in a constantly unsettled condition. There has been and remains great dispute over the basic unit or units of ecological discourse - individuals, species, populations, communities, ecosystems or still larger entities; there is disagreement over the existence, character or relative importance of various ecological generalizations - succession, biogeochemical cycling, competitive exclusion; there is now available a host of research methods, undue allegiance to any one which might, as is always the case in the sciences, commit the investigator to one interpretive strategy and exclude other, perhaps promising possibilities. As noted, McIntosh has not elected to develop his history along these thematic lines.

One should attempt to do so, however, for what is needed today, in addition to detailed chronological accounts such as that offered here, is equally detailed analysis of several questions in the history of ecology. We need to know, for example, how and why animal ecology followed a course different from that of plant ecology; why population phenomena rose to the fore during the 1920s and 1930s; what role, if any, ecology played in the evolutionary modern synthesis; what have been the advantages of large-scale scientific research; and what have been the factors behind the shifting emphasis upon cooperative and competitive ecological models. We still need, despite the flood of literature seemingly directed to the topic, a clear view of the relationship of ecology as an aspiring natural science and the environmental movement as a political, social and moral campaign. The historian's obligation is to address such matters and not to rest content with a chronicle of events.

The Background of Ecology offers excellent preparation for such study. The author omits very little in the AngloAmerican tradition - Continental ecology was not part of McIntosh's brief - and provides an up-to-date and virtually exhaustive bibliography of relevant primary and secondary materials. Moreover, his classification of doctrinal tendencies and portrayal of leading controversies provides a valuable guide to a vast and still largely uncharted sea. Regrettably, only within certain of its sections is McIntosh's volume a work of incisive interpretation, but it is throughout a reference work of distinction and one which is sure to be of interest to ecologists as well as to historians.

William Coleman is Dickson-Bascom Professor in the Humanities and Professor of History of Science and History of Medicine at the University of Wisconsin, Madison, Wisconsin 53706. USA.

\section{Private life of radiochemistry}

\section{Alwyn M'Kay}

George de Hevesy: Life and Work. By Hilde Levi. Rhodos International, Copenhagen/Adam Hilger: 1985. Pp.147. DKr.120, £15, $\$ 25$.

GEORGE de Hevesy (1885-1966) was one of the great pioneers of radiochemistry, perhaps the greatest. He invented many of the principal radiotracer techniques, for which he was awarded the 1943 Nobel Prize for chemistry, and the radiochemical textbook he wrote jointly with Fritz Paneth was for years the standard work on the subject. Though a chemist, he has been called "the father of nuclear medicine", since it was to a large extent through his efforts that this field was opened up.

There is, however, surprisingly little in print about the man himself. There are three obituaries, one based almost entirely on his autobiographical notes, but not much else. It is fortunate that his longserving assistant has given us this book.

Hevesy emerges as an enigmatic figure. He was aristocratic, courteous, reserved; one seldom talked to him about anything but science and its affairs. He took immense pleasure in his work, which is on record for all to see, but revealed little of his inner self, even in his letters to his closest friends. Life is more than science, yet Levi has been able to record no word of Hevesy's on religion or art, hardly anything on his family, and surprisingly little on political affairs considering that Nazism forced him to move from Germany to Denmark in 1934 , and then to Sweden in 1943. Having a Hungarian passport, he could make these journeys freely despite being Jewish.

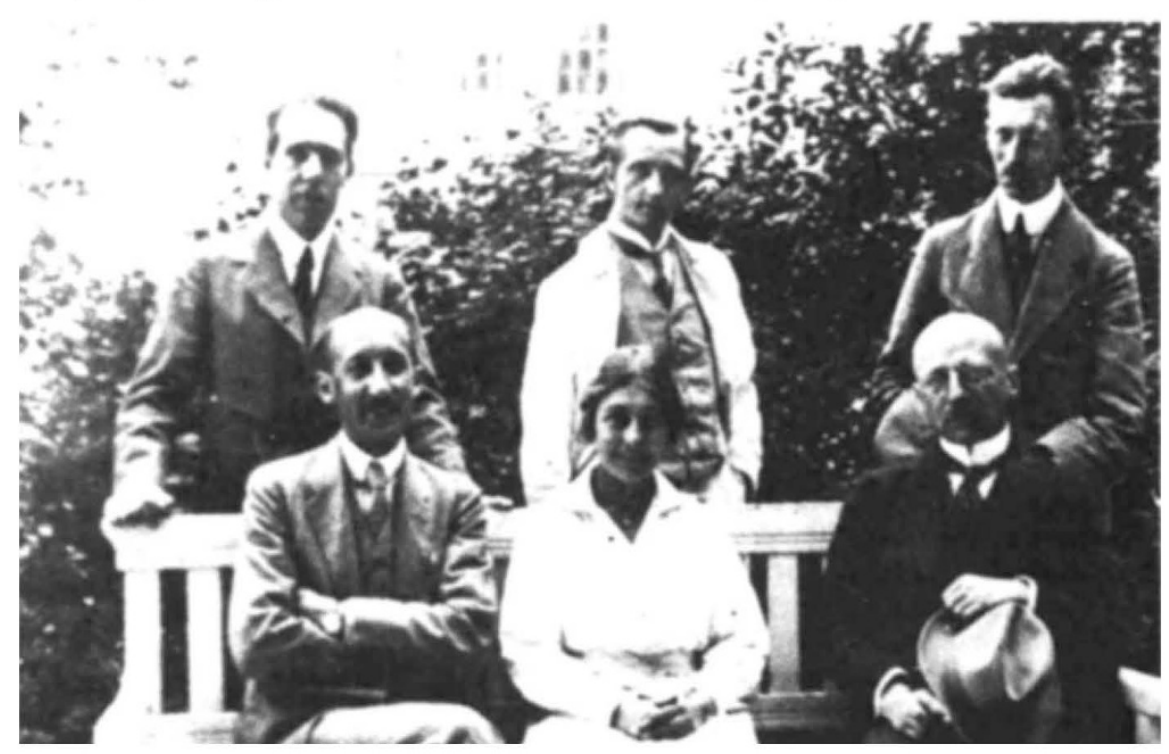

Meeting of minds - Haber's visit to Copenhagen in 1921. Standing: Neils Bohr. E Güntelberg and I. Brønsted. Seated, G. Hevesy. Mrs A. Delbanco and Fritz Haber
The book provides some illuminating sidelights on Niels Bohr, in whose Institute Hevesy spent two long and fruitful periods (1920-1926 and 1934-1943), at Bohr's personal invitation. Bohr admired Hevesy's abilities, which were very different from his own, and eagerly encouraged him to launch into the almost unof these periods, arranging for Levi to become his assistant. She naturally describes the resultant scientific achievements in some detail, from first-hand knowledge.

Hevesy's earlier applications of radiotracers to physicochemical problems, starting from work under Rutherford in 1911 and 1912 in Manchester, receive less attention. So long as the only tracers available were the natural radioelements, the only quantities he could measure, such as the solubility of lead chromate, were of limited interest in themselves. There was, however, great originality in his physicochemical ideas, which laid the foundations of the tremendous later developments in the use of radiotracers.

The author's command of English is generally excellent, but in places the text would have benefited from the attentions of a sub-editor. A particular point which may mislead is the use of the phrase "first of all", not in a temporal sense, but to mean "above all" or "primarily". Such small blemishes apart, the book tells its story well. Scientific matters are lucidly described (though the layman may find certain passages difficult even with the aid of the glossary provided) while the biographical material will be of interest to anyone concerned with the history of physics and chemistry in the twentieth century.

Alwyn M'Kay, Thurso, 40 Lockstile Way, Goring, Reading RG8 OAL. UK, was formerly a Group Leader at the Atomic Energy Research Establishment, Harwell. He worked with Hevesy in Copenhagen between 1935 and 1937. charted area of radiobiology in the second 